\title{
La democracia dictatorial pinochetista: regionalización y municipios
}

\section{Pinochet's dictatorial democracy: regionalization and local government}

\author{
Verónica Valdivia Ortiz de Zárate \\ Universidad Diego Portales \\ Académica Escuela de Historia \\ (Chile) \\ veronicavaldiviaoz@gmail.com
}

Este artículo analizará el proceso de regionalización impulsado por la dictadura del general Augusto Pinochet, a fines de los años setenta. Nuestra hipótesis es que en el caso chileno la modernización económica era condición para la despolitización social, la redefinición de la política y la construcción de una nueva “democracia”. La regionalización permitía escalonar la participación, centralizando las decisiones importantes en el nivel nacional y regional, relegando la incorporación ciudadana al último nivel, el escalón comunal. La "democracia" pinochetista sería comunal.

Palabras Clave: Dictadura - Pinochet - Regionalización - Democracia - Municipios

\begin{abstract}
This article explores the regionalization process promoted by General Augusto Pinochet's dictatorship towards the end of the '70s. According to our hypothesis, economic modernization was a precondition for Chile's social depoliticization, the redefinition of politics, and the making of a new "democracy". Regionalization allowed a staggered participation, where the most important decisions were centralized at a national or regional level, while grassroots citizen activity remained relegated to the lowest rung, the local level. Pinochet's "democracy" would be of a municipal nature.
\end{abstract}

Key Words: Dictatorship - Regionalization - Democracy - Municipal government 


\section{Introducción}

E1 Chile de la postdictadura se caracterizó por un creciente proceso de desafección política, en contradicción con la alta movilización social en la lucha contra la dictadura pinochetista. A cuatro años del fin de aquella, importantes sectores de la juventud dejaron de incorporarse a los registros electorales, produciéndose un significativo aumento en la abstención electoral, la cual alcanzó el 30\% en las parlamentarias de 1997 y siguió subiendo en los años siguientes. Simultáneamente, el país era sindicado como un "modelo" de transición a la democracia, pues no se produjeron regresiones autoritarias, y se crecía a importantes tasas, erradicando los altos índices de pobreza heredados de la dictadura. ${ }^{1}$ Para fines de los años noventa, este exitismo empezó a batirse en retirada, considerando el peso que aún tenía el proyecto dictatorial y cuestionándose el tipo de transición democrática llevada a cabo. Por ello cobró vigencia la noción de postdictadura o postpinochetismo, como expresión del debilitamiento de la frontera entre democracia y dictadura. ${ }^{2}$ Parte de esa crítica era el problema de la desafección política.

Aunque el neoliberalismo ha tenido ese efecto en todo el mundo, ${ }^{3}$ en Chile ha sido

1. DRAKE, Paul y JAKSIC, Iván, El modelo chileno. Democracia y desarrollo en los noventa, Lom, Santiago, 1998; CAMPERO, Guillermo, "Más allá del individualismo: la buena sociedad y la participación", en CORTAZAR, René y VIAL, Joaquín (editores) Construyendo opciones, Dolmen/Cieplán, Santiago, 1998.

2. GARRETON, Manuel Antonio, Del postpinochetismo a la sociedad democrática, Debate, Santiago, 2007.

3. BAUMAN, Zigmunt, Vida de consumo, Fondo de Cultura Económica, México, 2007 y BAUMAN, Zigmunt, En busca de la política, Fondo de Cultura

172 asociado a la masificación del consumo, a una cultura individualista y hedonista, que alteró la forma de entender la política, ${ }^{4} \mathrm{y}$ a la herencia de la dictadura y la represión. ${ }^{5}$

Desde el punto de vista de este trabajo, el fenómeno de despolitización en Chile debe analizarse en una perspectiva de mediano plazo, poniendo atención en el proyecto político de la dictadura y su legado. En general, existe consenso en que la dictadura pinochetista buscaba despolitizar a la movilizada sociedad chilena de los sesenta y principios de los setenta, siendo la represión y el neoliberalismo sus instrumentos más importantes. ${ }^{6}$ Desde otra óptica, se puso atención en el proyecto autoritario y antidemocrático implementado, destinado a proyectarse una vez finalizada ella,

Económica, Buenos Aires, 2001; ROSANVALLON, Pierre, La contrademocracia, Manantial, Buenos Aires, 2011.

4. LECHNER, Norbert, Las sombras del mañana. La dimensión subjetiva de la política, Lom, Santiago, 2002; MOULIAN, Tomás, El consumo me consume, Lom, Santiago, 1998; DRAKE, Paul y JAKSIC, Iván, El modelo chileno..., Op. Cit.; GARRETÓN, Manuel Antonio, Neoliberalismo corregido y progresismo limitado. Los gobiernos de la Concertación en Chile 1990-2010, Clacso/ Arcis, Santiago, 2012.

5. CAMPERO, Guillermo, "Más allá del individualismo...”, Op. Cit.; VALDIVIA, Verónica, "La alcaldía de Joaquín Lavín y el "lavinismo" político en el Chile de los noventa”, en www.historiapolitica. com, Buenos Aires, 2012, Dossier Chile Contemporáneo, Disponible en: http://historiapolitica.com/datos/ biblioteca/chile_ortizdezarate.pdf.

6. GARRETON, Manuel Antonio, El proceso politico chileno, Flacso, Santiago, 1984; LECHNER, Norbert, Los patios interiores de la democracia, Fondo de Cultura Económica, México, 1990; GARRETON, Manuel Antonio, La conflictiva y nunca acabada construcción del orden deseado, Flacso, Santiago, 1984; BRUNNER, José Joaquín, La cultura autoritaria en Chile, Flacso, Santiago, 1982. 
impidiendo rebrotes democratizadores. ${ }^{7}$

A nuestro entender, la dictadura combinaba intereses de orden económico y político, los cuales se imbricaban en su preocupación por el crecimiento del marxismo y la denominada subversión, los que eran asociados al atraso y la pobreza. En Chile, la subversión era entendida como producto de la falta de desarrollo y su impacto social, por lo cual la despolitización requería de dos procesos: una ola modernizadora y una modificación de las lógicas políticas. Junto con el mercado y la represión, la regionalización y la reforma municipal de 1975-1979 fueron las herramientas definidas por la dictadura para lograr ese objetivo, toda vez que ellas permitían imponer el autoritarismo y recuperar la centralización estatal, dividiendo la gestión y la participación en tres niveles: nacional, regional y comunal. Mientras las decisiones proyectuales radicarían en el nivel nacional, en una elite reducida, su legitimación debería ocurrir en el escalón comunal, donde se materializaría la subsidiariedad estatal y la democracia dictatorial. De este modo, se redefinía el sentido de la participación como social y no política, territorial y no nacional.

Desde una óptica metodológica, este artículo utilizará alguna de la documentación oficial de la dictadura, desclasificada hace poco tiempo. En concreto, las Actas de la Junta de Gobierno, las Actas de los Consejos de Alcaldes, los Objetivos Nacionales y otros documentos publicados.

7. MOULIAN, Tomás, Chile actual. Anatomía de un mito, Lom, Santiago, 1997; ARRIAGADA, Genaro, Por la razón o la fuerza. Chile bajo Pinochet, Sudamericana, Santiago, 1998; CONSTABLE, Pamela y VALENZUELA, Arturo, A nation of enemies. Chile under Pinochet, New York, W.W. Norton \& Company, 1993.

\section{Estatismo y poder social en Chile}

Uno de los pilares de la tesis de la "excepcionalidad chilena" es el de la centralidad de su Estado en el desarrollo nacional y en la estabilidad política alcanzada en los siglos XIX y XX. Tras la crisis de Independencia, los sectores conservadores, vinculados a la hacienda, derrotaron a las vertientes liberales antiautoritarias y partidarias de la autonomía regional, provocando el ascenso del comerciante Diego Portales al poder, encarnación del triunfo conservador. El habría sido el artífice del "Estado en forma", esto es, autoritario, defensor del orden y el progreso, capaz de subordinar a todas las vertientes "anárquicas" dentro de la propia elite y sostenido en la subordinación del bajo pueblo, con quien los relacionaba, desde su óptica, una superioridad moral. Este Estado centralista colocó al país dentro del mercado mundial, amplió y consolidó su territorio, impuso el orden público y social, a la vez que generó un sistema político, social e ideológicamente elitista. El territorio empezó a ser cubierto por la estructura administrativa estatal: intendencias, gobernaciones, municipalidades, todas bajo dependencia del Ejecutivo y con clara hegemonía de la elite de Santiago. ${ }^{8}$

A pesar de este modelo estatista autoritario, el poder de las elites radicaba en importante medida en su control de la tierra

8. EDWARS, Alberto, La fronda aristocrática, Imprenta Nacional, Santiago, 1928; GONGORA, Mario, Ensayo bistórico del Estado en Chile en los siglos XIX y XX, Ediciones La Ciudad, Santiago, 1981; FERNANDEZ, Enrique, Estado y sociedad en Chile, 1891-1931. El Estado excluyente, Lom, Santiago, 2003, p. 6. 
y del campesinado en los latifundios, el cual manejaba con absoluta independencia del aparato estatal. En ese sentido, el predominio sobre el Estado era combinado con un amplio poder económico, social y cultural, de modo que la oligarquía controlaba al Estado, pero el Estado no la controlaba a ella, en tanto éste era una extensión de su patrimonio. Hay quienes observan en esto una mirada escéptica del poder estatal, ${ }^{9}$ esto es, controlar el Estado para impedir su fortalecimiento, por lo que la esfera de lo estatal solo se remitía a la defensa del territorio, el orden público, algunos servicios sociales (correos, transporte, oficialización de documentos), interviniendo sobre aspectos mínimos de la sociedad, salvo en materias represivas.

Esta complementariedad entre poder estatal y poder local/oligárquico se redefinió a partir de 1891, cuando el Presidente liberal José Manuel Balmaceda intentó colocar al Estado por sobre el poder oligárquico, desafío resuelto con una guerra civil ganada por los grupos antiestatales, los que erosionaron su poder, instalaron un orden parlamentarista y fortalecieron el poder de la oligarquía a escala local. En 1891, se decretó la "comuna autónoma”, que radicó en los municipios el control de las policías, como de las elecciones, sustrayéndolas del Estado central, enlazando el poder parlamentario y comunal. Aún así, la estructura estatal creada antes y que cubría el territorio se expandió con la riqueza salitrera: escuelas, ferrocarriles, registro civil, correos

9. Una crítica a la tesis del Estado en forma en ILLANES, María Angélica, Chile des-centrado, Lom, Santiago, 2003; JOCELYN-HOLT, Alfredo, El peso de la noche. Nuestra frágil fortaleza histórica, Planeta, Santiago, 1998. y telégrafos, ${ }^{10}$ permitiendo a las oligarquías locales disponer de la institucionalidad para su propio beneficio.

Cuando este poder oligárquico se veía ensombrecido por la rebelión de los nuevos actores surgidos de la modernización, trabajadores urbanos, mineros y portuarios, inspirados en el socialismo y el anarquismo, su respuesta fue reforzar los dispositivos coercitivos del Estado, tales como las policías y el uso de las fuerzas armadas, en lugar de legislar sobre los graves problemas laborales y sociales que aquejaban al país. ${ }^{11}$

Fue contra este sistema de dominación que sectores reformistas, civiles y militares, se rebelaron en 1920, proponiendo un programa de integración nacional y fortalecimiento del Ejecutivo y del aparato estatal, el que fue dotado de nuevas facultades económicas y sociales. Esta noción integrativa supuso legitimar la participación política popular, a través de la potenciación de organizaciones sociales de base, especialmente sindicatos de escala nacional, pero dependientes del Estado, pues esta reforma buscaba una integración disciplinada de los trabajadores y funcional al orden capitalista vigente. La reforma de los años veinte supuso una mayor centralización estatal, por su papel en el proceso de

10. FERNANDEZ, Enrique, Estado y sociedad..., Op. Cit.

11. DEVES, Eduardo, Los que van a morir te saludan, Documentas, Santiago, 1987; GARCES, Mario, Crisis social y motines populares en el 1900, Documentas, Santiago, 1991; BOHOSLAVSKY, Ernesto y HARAMBOUR, Alberto, "El miedo rojo más austral del mundo. Clase dominante local y Estado nacional frente a los trabajadores en la Patagonia argentina-chilena (19171922)", en MASSES, Enrique y GALLUCCI, Lisandro (editores) Historia de los trabajadores en la Patagonia, Universidad de Comahue, Neuquén, 2007. 
industrialización, en el bienestar social, como en la redefinición de los dispositivos coercitivos. La anterior estructura estatal fue reforzada con la ampliación de la educación pública, la salud, el transporte terrestre y marítimo, la explotación minera, pero también una policía paramilitar y un organismo de inteligencia civil bajo dependencia del Ejecutivo, esparcidos por el territorio nacional. Todo un sistema de control social fue instalado en el Ministerio del Interior. ${ }^{12}$ Esta centralización confirmó la dependencia de las provincias y municipios de los recursos del Estado, pero también del sistema sindical, cuyas demandas debían atenerse a las lógicas estatales.

No obstante, y tal como ocurrió en el siglo XIX, este crecimiento del poder estatal nacional, fue a la par de la subsistencia del poder local latifundista, pues un pacto entre las fuerzas políticas a fines de la década de 1930 aseguró la industrialización a condición de no realizar la reforma agraria, manteniendo al latifundio y al poder oligárquico sobre la tierra y el campesinado. Este pacto de dominación excluyó a los campesinos de los derechos sociales y permitió a la oligarquía usufructuar de sus derechos políticos, controlados desde el latifundio, lo cual le permitía tener una sobrerrepresentación parlamentaria, pudiendo negociar las iniciativas de reformas provenientes de la centro-izquierda y bloquear aquellas que perjudicaban sus intereses. La "guerra de posiciones" desplegada por la oligarquía, a través de sus estructuras partidarias y las asociaciones empresariales,

12. ROJAS, Jorge, La dictadura de Ibáñez y los sindicatos, Dibam, Santiago, 1993; MORRIS, James, Las elites, los intelectuales y el consenso, Fora, Santiago, 1970; VALDIVIA, Verónica, "Los tengo plenamente identificados. Seguridad interna y control social en Chile, 1918-1927”, mimeo. fue penetrar el aparato estatal, morigerando los planes gubernativos originales de la centroizquierda y defendiendo sus privilegios. ${ }^{13}$

Como se observa, a pesar de todo el crecimiento experimentado por el aparato estatal, la oligarquía logró frenar su expansión en el mundo rural y profitar del impulso industrializador. Este frágil equilibrio entre centralización estatal y poder local comenzó a estallar en los sesenta cuando los proyectos de transformación estructural provenientes del social cristianismo, la izquierda marxista y los de la derecha colisionarían. En efecto, decididos a enfrentar el arcaísmo oligárquico, el gobierno democratacristiano inició la reforma agraria y el proceso de nacionalización del cobre, otorgando derechos ciudadanos al campesinado y los "pobladores", habitantes de míseras barriadas. Este proceso fue profundizado durante la experiencia de la Unidad Popular (UP), cuando el Estado, en tanto empresario, creció exponencialmente al nacionalizar la propiedad industrial, financiera y comercial, aplicando en toda su intensidad la ley de reforma agraria, a la vez que se ampliaron los derechos sociales. Una "revolución por arriba" estaba ocurriendo.

Simultáneamente, una revolución "por abajo" tenía lugar, pues las orgánicas sociales desbordaron los planes participativos de la UP, pensados desde el Estado y para ser colocados bajo su tutela, apostando por opciones socializadoras más radicales. Mientras el latifundio desapareció, cientos de empresas fueron expropiadas por los trabajadores. En ninguno de estos casos, sin embargo, la acción popular se propuso fortalecer el poder

13. GOMEZ, Juan Carlos, La frontera de la democracia, Lom, Santiago, 2004. 
regional ni municipal, sino tomar el Estado, desde donde se implementarían los cambios estructurales que se esperaban llevar adelante. ${ }^{14}$ La revolución por arriba y por abajo amenazó el papel social del capital y del empresario, constituyéndose en una de las experiencias más peligrosas de la región en esos años. ${ }^{15}$

Las derechas, por su parte, sufrieron una importante mutación ideológica. Elliberalismo, que había sido su matriz doctrinaria, retrocedió, siendo profundamente penetrado por las ideas corporativas antiestatales, provenientes del tradicionalismo católico y del nacionalismo franquista; ellas fueron complementadas con las corrientes neoliberales, originadas en la Escuela de Chicago, las que apostaban por la reposición del mercado, el debilitamiento de los sindicatos y del aparato estatal, fortaleciendo la alianza con las multinacionales. La síntesis neoliberal-corporativa abandonó la tendencia cooptativa del cambio y recogió la antigua tradición oligárquica de escepticismo frente al Estado, en materia económica y social, como respecto de la soberanía popular. ${ }^{16}$

Ese fue el escenario en que se produjo el golpe de Estado de 1973. Tanto las derechas, parte significativa del centro político y las

14. WINN, Peter, La revolución chilena, Lom, Santiago, 2013; GAUDICHAUD, Franck, Chili 1970-1973. Mille jours qui ébranlerent le monde, Presses Universitaires de Rennes, París, 2013.

15. O'DONNELL, Guillermo, El Estado Burocrático Autoritario, Belgrano, Buenos Aires, 1982.

16. CORREA, Sofía, Con las riendas del poder, Sudamericana, Santiago, 2004; VALDIVIA, Verónica, Nacionales y gremialistas. El 'parto' de la nueva derecha politica chilena, 1964-1973, Lom, Santiago, 2008; CRISTI, Renato y RUIZ, Carlos, El pensamiento conservador en Chile, Editorial Universitaria, Santiago, 1992. fuerzas armadas rechazaron los niveles de estatización alcanzados, estando decididos a reducir el tamaño y el papel económico-social del Estado, como la amplia concepción de ciudadanía que predominó entre 1967 y 1973.

\section{Regionalización: escalonando la participación}

Pocos meses antes del golpe, a principios de julio de 1973, las fuerzas armadas emitieron un Memorandum, ${ }^{17}$ en el cual rechazaron la acción estatal sobre el derecho de propiedad privada, pues el Estado había expropiado empresas y predios agrarios y urbanos por sobre la ley, controlando cientos de ellas. Esto suponía un exceso de estatismo. Contrariamente, el apoyo histórico del Estado al mediano y pequeño empresariado se había abandonado, permitiendo que las tomas y las huelgas avanzaran, sin usar los dispositivos coercitivos. $\mathrm{La}$ indisciplina social y los grupos armados se habían enseñoreado del país, frente a un Estado inactivo. Tal situación requería de un rediseño estatal.

Este documento es importante porque refleja el estadio del pensamiento militar en los meses inmediatos al golpe. No existía un desconocimiento total del papel económico y social del Estado, pero éste debía atenerse a la promoción de la iniciativa privada, verdadero motor del desarrollo, reservándose la propiedad estatal a las industrias estratégicas.

17. "Memorandum", 4 de julio de 1973. En la confección de este documento participaron representantes de los altos mandos de las tres ramas de las FFAA, del cual salió el núcleo del golpe, conocido como "Grupo de los 15”. GONZÁLEZ, Mónica, La conjura. Los mil y un días del golpe, Ediciones Bat, Santiago, 2001 y 2a Edición, Catalonia, Santiago, 2012. 
Por ello, existía la firme convicción sobre la desestatización del grueso de las empresas expropiadas, en una reforma agraria sujeta a la ley de 1967, devolviendo a los privados el protagonismo en el desarrollo, y la urgencia en disciplinar al mundo popular. En ese sentido, en el caso de Chile se produjo una complementación entre la antigua tradición doctrinaria castrense, estatista y de integración social, pero muy anticomunista, denominada "Ibañismo", y las tesis de la Doctrina de Seguridad Nacional, que enfatizaban la conexión entre seguridad y desarrollo, en el marco de la transnacionalización de la economía mundial, y la idea de un enemigo interno. $^{18}$

Este antiestatismo, sin embargo, solo relativizaba lo económico-social, pues la geopolítica y la Doctrina de Seguridad Nacional debían ejercer fuerte influencia en otras áreas del desarrollo estatal, como aquellas relacionadas con la seguridad, el control territorial y la política. Desde ese punto de vista, la dictadura volvió a definir la relación entre sociedad y Estado, retomando la tradición decimonónica de fuerte centralismo en la toma de decisiones, estableciendo una jerarquía en los distintos niveles y asegurando la subordinación social, condición del desarrollo económico y la seguridad.

En este proceso la geopolítica jugó un papel crucial, pues ella ofrecía respuestas a problemas concretos y permitía definir objetivos y políticas. La concepción orgánica-geopolítica del Estado, como organismo territorial, fue interpretada como "seguridad y desarrollo",

18. VALDIVIA, Verónica, El golpe después del golpe. Leigh vs Pinochet (Chile, 1960-1980), Lom, Santiago, 2003; VERGARA, Pilar, Auge y caída del neoliberalismo en Chile, Flacso, Santiago, 1985. facilitando la identificación de objetivos nacionales consistentes con las características geográficas del país y la idiosincrasia de su población. La oficialidad veía la marginalidad y la pobreza, suscitada con la migración campo-ciudad, como una de las razones más importantes para la seducción del marxismo y la subversión. Por ello, si bien no se repondría el protagonismo empresarial del Estado, el país requería de un nuevo impulso económico que permitiera recuperar el crecimiento y erradicar la pobreza. ${ }^{19}$

En concreto, el problema político estaba estrechamente unido al económico, pues según la óptica militar la subversión tenía su raíz en la pobreza y la marginalidad. De allí, que el plan de reorganización territorial y estatal buscaba enfrentar ambos desafíos: impulsar el desarrollo y subordinar al populacho y a la subversión.

Estas preocupaciones estuvieron presentes en la creación de la Corporación Nacional de Reforma Administrativa (CONARA) y la regionalización (1973), considerando criterios regionales, demográficos y económicos, de modo de integrar territorialmente al país, aprovechando mejor los recursos naturales, la distribución geográfica de la población y la seguridad nacional para establecer las bases de un desarrollo racional de las regiones y evitar los desequilibrios que favorecían la migración campo-ciudad y sus correlatos de marginalidad

19. Archivo del Congreso Nacional, Actas de la Junta de Gobierno, "Exposición de la Comisión Nacional de Reforma Administrativa", Acta No 59, 27 de diciembre de 1973, Acta No 113-A; 16 de abril de 1974 y Anexo de Acta No 61 de 8 de enero de 1974; VALDIVIA, Verónica, "Al rescate del Municipio. La síntesis ideológica de la dictadura pinochetista", Observatorio Latinoamericano, Buenos Aires, agosto 2011, No 8, Dossier Chile. 
y subversión. Así, la regionalización no era sólo una medida de orden territorial, sino un "instrumento de gobierno, de participación, de administración, que sirve para alcanzar los objetivos de integración nacional, seguridad y desarrollo". ${ }^{20}$ Este propósito debía cumplirse a través de un proceso de des-centralización, según rezaba el discurso castrense: "descentralización con niveles de desarrollo propios y estos referidos a unidades territoriales, cada una con sus respectivas autoridades... con poderes de decisión equivalentes de modo que sea posible su integración... mediante instituciones que las obliguen a proceder en conjunto y no aisladamente... que el desarrollo sea una función preferente del Estado, junto a otro aspecto de orden y seguridad". ${ }^{21}$ Coincidente con la Declaración de Principios de marzo de 1974, la Comisión hacía suya la definición del Estado como unitario, pero descentralizado administrativa y regionalmente para la coordinación y participación de las diferentes regiones. ${ }^{22}$

No obstante, este discurso descentralizador no debía confundirse con una "federalización... la autonomía regional se refiere únicamente a una categoría específica de toma de decisiones y de proposiciones al gobierno central para materializar de mejor forma la participación. En términos de comparación histórica, el proceso centralizador tiene cada vez más vigencia. Sin embargo, para Chile se requiere grados de descentralización por motivos geográficos". ${ }^{23}$ A partir de estos principios, la

20. Actas de la Junta de Gobierno, Acta 119-A, 30 de abril de 1974, p. 2.

21. Ibídem.

22. Junta de Gobierno, Declaración de Principios, Editora Gabriela Mistral, Santiago, 1974.

23. Acta No119, p. 3

178
Comisión proponía una estructura de gobierno y administración nacional, regional y comunal.

Si bien la Constitución de 1925 -en teoría aún vigente- contemplaba un proceso de descentralización administrativa gradual, ésta no se implementó, por lo que la Comisión proponía "ampliar el concepto de descentralización administrativa a los de desconcentración del poder, que implica que el proceso de toma de decisiones deja de estar en pocas manos para que, con mecanismos regulados, pase a estar en manos de muchos más con suficientes facultades y a través de mecanismos de participación que signifiquen una consulta permanente a los organismos de la comunidad en los distintos niveles que correspondan". ${ }^{24}$ Para ello se establecerían mecanismos de decisión, administración y asesoría para cada nivel; la división territorial debería seguir la lógica del Estado unitario, que permitiera una secuencia lógica en la toma de decisiones y el desarrollo del país, todo lo que debería insertarse "dentro de un sistema nacional de planificación, armónico, integral y participativo... que signifique una nueva y moderna institucionalidad de una descentralización del poder, tanto en lo funcional como en lo territorial, lo cual permitirá al país avanzar hacia una sociedad reivindicada y de verdadera participación social". ${ }^{25}$

La regionalización estaba en el horizonte de un amplio sector político en Chile, pues el centralismo era una sombra en su historia, sinónimo de autoritarismo. Por eso, durante el gobierno de la DC (Democracia Cristiana), la Oficina de Planificación

24. Ídem, p. 25

25. Ídem, pp. 25-26 
Nacional (ODEPLAN) inició los estudios. En el caso de las Fuerzas Armadas, sin embargo, incidían las descoordinaciones que provocaban en el desarrollo del país y la falta de eficiencia, percepciones que se imbricaban con la geopolítica y la conexión entre seguridad y desarrollo de la Doctrina de Seguridad Nacional, todo lo cual reactualizaba el centralismo, pero bajo un nuevo discurso. La presentación de la Comisión de Reforma Administrativa ante la Junta de Gobierno, apuntaba a una desconcentración del poder, más que a una descentralización. Esta, como es sabido, se relaciona con formas de poder local, antiestatales, poderes subregionales, pero el informe de CONARA solo se refería a ejecución de medidas, no a la autonomía de las autoridades, que seguían bajo la autoridad central. De allí que la pretensión era la "simplificación del proceso de toma de decisiones, que apoye la eficiencia, la probidad y la responsabilidad administrativa; que asocie y coordine los procesos decisionales y los de asignación de recursos; los compatibilice en los distintos niveles, buscando permanentemente objetivos coherentes entre el desarrollo nacional, regional y subregional". ${ }^{26}$ Para ello, era necesario reformar la Constitución de 1925 para dividir al país en regiones, éstas en provincias y aquellas en comunas. La nueva administración requeriría la delegación de facultades y la creación de niveles organizados jerárquicamente. De acuerdo a ello, el nivel nacional o central era entendido como "núcleo o eje principal del sistema, el que reconoce o delega atribuciones y funciones, manteniendo responsabilidad por las acciones que se generan. Ello no implica el debilitamiento del poder central, sino que por el contrario, el ejercicio del poder delegado, debidamente supervisado, lo

26. Ídem, p. 26 robustece al convertir en decisiones y acciones, que siguiendo su propio pensamiento y superior (sic) instrucciones, manifestará en resultados que apoyarán su gestión y caracterizarán su base de sostenimiento". ${ }^{27}$

Esta reivindicación del poder central era consistente no solo con la historia del país, sino con una mentalidad militar, jerárquica, pero a la que se sumó la particularidad del proceso dictatorial chileno. Las dictaduras de los años setenta se caracterizaron no sólo por la uniformidad ideológica bajo las tesis de la seguridad nacional y la guerra revolucionaria, sino también por la participación institucional de las Fuerzas Armadas en la toma del poder. Ello supuso una decisión colegiada, evitando la personalización o los caudillismos. ${ }^{28} \mathrm{La}$ dictadura chilena revistió una particularidad dentro de esta tendencia general al combinar un régimen institucional, pero con una fuerte personalización del poder, encarnada en el general Augusto Pinochet, generándose un "pinochetismo". ${ }^{29}$ Esto supuso una concentración de atribuciones en Pinochet, pero que no anularon del todo la opinión del ejército en su conjunto, el que fue mantenido al margen de las decisiones, pero presente a través de CONARA y del Comité Asesor de la Junta (COAJ), expresivo de los intereses y tendencias castrenses. El COAJ asesoraba directamente a Pinochet, preparando informes

27. Ídem, p. 28. El énfasis es nuestro.

28. CANELO, Paula, El proceso en su laberinto. La interna militar de Videla a Bignone, Prometeo, Buenos Aires, 2007; NAPOLITANO, Marco, 1964. História do regime militar brasileiro, Editora Contexto, Sao Paulo, 2014.

29. CONSTABLE, Pamela y VALENZUELA, Arturo, A nation of enemies..., Op. Cit., cap. 3; VALDIVIA, Verónica, "Pinochetismo e guerra social no Chile", en PATTO, Rodrigo, Ditaduras Militares. Brasil, Argentina, Chile e Uruguay, Editora UFMG, Belo Horizonte, 2015. 
y programas, y manteniéndolo informado del clima interno. Esta concentración del poder en Pinochet se materializó en una separación institucional entre las tareas del Ejecutivo, asociado a la Presidencia, cargo que recayó en Pinochet en 1974, y la legislatura, que asumió la Junta Militar, con lo cual se retomó el presidencialismo histórico. Asimismo y a medida que las rivalidades entre las tendencias más corporativistas, representadas por el Comandante en Jefe de la Fuerza Aérea, y la atracción que los neoliberales ejercieron sobre Pinochet, se agudizaban entre 1973 y 1978, se acentuó la personalización del régimen. Habiendo escogido la modernización neoliberal,Pinochet reforzó su poder a través de la represión, vinculando al principal organismo de seguridad, la DINA, a su autoridad; la asesoría de un grupo de tecnócratas, juristas y publicistas que lo reforzaba en los debates programáticos y en materia de imagen, desvinculando a las fuerzas armadas de las tareas políticas y generándose una base de apoyo social entre las mujeres, los jóvenes y algunos sectores laborales. Para 1978 ya se hablaba de "pinochetistas". 30

En concreto, en la recuperación de las tendencias centralistas influyeron no sólo la tradición histórica de Chile, sino también las

30. VALENZUELA, Arturo, "Los militares en el poder. La consolidación del poder unipersonal”, en DRAKE, Paul y JAKSIC, Iván (editores) El difícil camino a la democracia en Chile, Flacso, Santiago, 1993; HUNEEUS, Carlos, El régimen de Pinochet, Sudamericana, Santiago, 2001; VALDIVIA, Verónica, "Construction du poivoir et régime militaire sous Augusto Pinochet", en Vingtième Siècle. Revue D'Histoire, París, janvier-mars, 2010, Sciencies.Po. Les Presses, No 105; VALDIVIA, Verónica "Were Women and Young People the Heart of the Pinochet Regime? Rise and Decline of Secretariats", en Hispanic American Historical Review (HAHR), Durham, 2013, V. 93, No4. Consúltese también el Acta No 73 de 18 de enero de 1974. doctrinas militares en boga, que enfatizaban la cuestión de la seguridad, y la pinochetización del régimen.

Considerando la evaluación hecha por CONARA, el nivel nacional se expresaría en la estructura superior del Estado, alcanzando la totalidad de la realidad nacional. El nivel regional, entendido como unidad territorial con características geográficas, demográficas y de recursos naturales, formaría una unidad administrativa y económico-social, susceptible de gobernarse con eficiencia. La región era la base territorial de la administración del Estado, pues conjugaba los intereses nacionales con los locales y se asentaban en ella los servicios públicos y organizaciones sociales interdependientes. Este nivel regional se subdividiría en provincias, útiles al gobierno interior, de administración y planificación, de fiscalización y coordinación de las municipalidades, las que impulsarían el desarrollo social, pues en "esa escala [la municipal] se destacan de mejor forma los problemas de la convivencia humana". ${ }^{31}$ De acuerdo a este plan, el sistema estaría jerárquicamente organizado, ocupando su cúspide el Jefe de la Nación, general Augusto Pinochet, a partir del cual se definían los otros niveles.

Tal cual lo expuso el general Gustavo Leigh, Comandante en Jefe de la Fuerza Aérea hasta 1978, ante la Junta Militar. La estructuración social tenía tres niveles: nacional, regional y comunal. ${ }^{32} \mathrm{El}$ nivel nacional correspondía al sector público, esto es, los ministerios de

31. Acta No 119-A, p. 29. También Acta No 59..., Op. Cit.

32. Esta información está tomada de Actas de la Junta de Gobierno, Acta No 143, 1 de agosto de 1974. 
Interior, Educación, Justicia, Defensa, Obras Públicas, Agricultura, Trabajo, Salud Pública, Vivienda, Transporte, Secretaría General de Gobierno, el Director de ODEPLAN, el Asesor Cultural, Subsecretario de Hacienda, de Economía, Director de Información, Secretaría Ejecutiva del Consejo, es decir, lo que se consideraba el área social. Este nivel nacional determinaba las metas que cada región debía alcanzar, las que eran definidas por los ministerios, la Junta o Pinochet. Estas metas debían presentarse financiadas, con indicación de ubicación, tiempo de demora; ODEPLAN las armonizaba con la política general de gobierno y sus prioridades, para luego enviarlas al nivel regional. La centralización pretendía, así, evitar las descoordinaciones entre los niveles y asegurar las metas nacionales; ODEPLAN organizaba y esa información llegaba al Intendente, ofreciendo una visión integral del proceso. En el nivel regional, estaría el Consejo Regional de Desarrollo (COREDE), formado por un organismo público y otro privado. El jefe regional era el Intendente, quien organizaría este Consejo con los jefes de los servicios públicos de la región, con la Cámara de Comercio, los representantes del gran empresariado y otras orgánicas sociales, ayudando a mejorar el plan ya diseñado. En este nivel “... comienza, por lo tanto, a participar y a entrar el sector privado en coordinación con el sector público y se aprovecha el talento creador de la región y se comienza a trabajar descentralizadamente y con autoridad por parte del jefe de la región". ${ }^{33}$ En concreto, lo que se integraba era el capital a la región para impulsar su desarrollo. En el nivel comunal, estaba el alcalde, quien era asesorado por la Oficina de Planificación Local y el Consejo Local de Desarrollo y

33. Ibídem. estaba pensado como el "escalón ejecutor, el brazo que materializaba el progreso de Chile, uniendo los tres sectores, público, privado y comunitario". ${ }^{34}$ En este nivel participaba el Estado, desde sus directrices y financiamiento central, los privados y la población, a través de las uniones comunales, que reunían a las juntas de vecinos. Es decir, la sociedad sólo podía participar en el nivel inferior de la administración del país y en calidad de asesor, sin poder decisorio, el cual recaía en el alcalde. Es importante destacar que el municipio carecería de autonomía, pues era entendido solo como materializador de políticas definidas centralmente; el nuevo municipio no apuntaba a un poder local independiente y soberano.

Toda esta estructuración requería de la definición de metas nacionales, las que se materializaron en el documento "Líneas de Acción" de marzo de 1974 y en el Objetivo Nacional de 1975, este último mucho más permeado por las tesis de la seguridad nacional. ${ }^{35}$

Esta centralización se conjugó con la alta militarización del régimen -superior a las dictaduras de Argentina o Brasil-, pues, aunque los uniformados fueron excluidos de las decisiones políticas, ellos prácticamente coparon el aparato estatal y administrativo a

34. Ibídem. Para el caso argentino GÓMEZ, Gabriela, "Un estudio comparativo de la presencia de ideas corporativistas en regímenes dictatoriales latinoamericanos: Argentina (1966-1973) y Chile (19731988)", Tesis de Maestría en Estudios Latinoamericanos, Universidad Nacional de San Martín, 2013.

35. Gobierno de Chile, 1974, Primer año de la reconstrucción nacional, Editora Gabriela Mistral, Santiago, 1974; Gobierno de Chile, Objetivo Nacional, Editora Gabriela Mistral, Santiago, 1975. Junta de Gobierno, Lineas de Acción de la Junta de Gobierno de Chile, Editora Gabriela Mistral, Santiago, 1974. 
lo largo de los años. Acorde a su importancia, todos los intendentes regionales fueron militares, como también los gobernadores, directores de empresas estatales y servicios públicos, rectores de universidades. De 133 ministros, entre 1973 y 1989, 67 fueron oficiales, de los cuales casi la mitad pertenecían al ejército. Como explica Valenzuela, en 1988 de 174 cargos de la administración pública, incluyendo ministerios, subsecretarías y servicios públicos, el $40 \%$ eran ocupados por militares. Los civiles entraron a ministerios claves en la neoliberalización del país, como Hacienda, Trabajo, y en la pinochetización del régimen, en Interior y la Secretaría General de Gobierno. Esta presencia protagónica de uniformados y del ejército acentuó la naturaleza centralista-jerárquica del sistema, pues Pinochet actuaba como Comandante en Jefe y como Presidente, desde diciembre de 1974, del cual estas autoridades dependían. ${ }^{36}$

De esta forma, aunque se produciría una drástica privatización de los distintos sectores económicos, de los servicios sociales y el Estado retrocedería sustancialmente en esas materias, el Estado fue el actor central en la radicalidad de la experiencia neoliberal chilena, pues la modernización estructural era un pilar de la despolitización de la sociedad, seducida por las ideologías debido a los niveles de atraso y pobreza. La mixtura entre regionalización y desconcentración, más que descentralización, permitirían, a su entender, destruir el vínculo entre subdesarrollo, pobreza y subversión.

36. HUNEEUS, Carlos, El régimen..., Op. Cit., pp. 187-207; VALENZUELA, Arturo, "Los militares en el poder...", Op. Cit., pp. 84-85

182

\section{La democracia dictatorial: el escalón comunal}

Como queda claro de la sección anterior, el papel de los distintos sectores sociales estaba unido a la cuestión administrativa y política. El agudo antipartidismo militar pretendió desde un comienzo romper el fuerte lazo entre los partidos y la sociedad, abandonando las ideas de ciudadanía y reemplazándolas por las de participación social, lo cual suponía escalonar la toma de decisiones y acotar los grados de injerencia de cada actor social en los distintos niveles. El núcleo de esta concepción estaba en la elitización de las decisiones de política general, las que radicarían en el nivel nacional, de modo de liberarlo de las presiones desde abajo que habían caracterizado a la política chilena del siglo XX. Para ello era necesario debilitar y/o controlar a los intermediadores, los partidos, los sindicatos y las organizaciones comunitarias, no sólo reemplazándolos en esa tarea, sino también modificando la noción de participación.

Era consenso que la acentuada politización de la sociedad chilena se debía al peso determinante de los partidos y su relación con el Estado, por lo cual desde los años sesenta se había estado experimentando en formas participativas que fortalecieran las orgánicas sociales. Ello, sin embargo, no atenuó el poder partidario, sino que lo confirmó, como también la presión sobre el Estado y la indisciplina social. Esta situación potenció el corporativismo antiestatal en la derecha, especialmente en aquella que se transformó en la base de apoyo al régimen, decidida a eliminar a los partidos de la institucionalidad a crearse, a través de una separación entre el 
poder político y el poder social: las personas sólo deberían expresarse como poder social, es decir, en las organizaciones comunitarias, en el escalón municipal, mientras el resto de las decisiones recaerían en el poder político, ubicado en la cúspide de la estructura. Los neoliberales, también furibundos antiestatistas y antipartidarios, reforzaron esas concepciones. Sin embargo, la profunda convicción en el individualismo y el papel del mercado derivaron en que el conjunto del pinochetismo -fuerzas armadas, derecha política, tecnócratas neoliberales y empresarios- recuperaran la noción de democracia para el régimen, reconociendo la existencia de los partidos, aunque muy disminuidos en sus atribuciones, como las del Parlamento. Un presidencialismo centralista reemplazaría a los partidos. Los sindicatos, por su parte, fueron abandonados como interlocutores entre la sociedad y el Estado y, tras sufrir los rigores de la represión, fueron debilitados con el énfasis en la producción primaria, la desindustrialización y la flexibilidad laboral. El trabajo informal, no sindicalizado, fue la tónica del mundo del trabajo. ${ }^{37}$

La "participación", por lo tanto, debería disociarse de lo "político", en tanto definición programática, como lo explicitó el primer objetivo nacional al definirla como "un estilo que lleve a todos los chilenos a incorporarse al quehacer de los núcleos en que se desarrolla su vida en comunidad". ${ }^{38}$ Esta definición

37. VERGARA, Pilar, Auge..., Op. Cit.; ARRIAGADA, Genaro, Por la razón o la fuerza..., Op. Cit.; CAMPERO, Guillermo y VALENZUELA, José, El movimiento sindical chileno en el capitalismo autoritario, Ilet, Santiago, 1981; ÁLVAREZ, Rolando, “¿Represión o integración? La política sindical del régimen militar (1973-1980)”, Historia, Santiago, 2010, No 43, V. II.

38. Junta de Gobierno, Líneas de Acción", Op. Cit., p. 91. explicitaba la relación entre estructuración social y participación; a cada nivel, un tipo de decisión y de participación. Las cuestiones concretas y locales, dependientes del plan general, serían preocupación del nivel inferior, el comunal, en el cual se reconocía la colaboración de los distintos actores sociales, a diferencia del nivel regional y nacional.

En efecto, la comuna apareció como el espacio ideal para transformarla política chilena. En consonancia con los debates sostenidos en la CONARA, como en la Junta de Gobierno, el municipio fue relevado, pues se encuadraba en el sentido del golpe de septiembre, esto es, la generación de un proceso que concertara a "todos los organismos del Estado y del pueblo en todos los niveles... [un] nuevo concepto de municipio... [restituyéndole] el papel trascendente e insustituible que deben cumplir como fuente de organización social" ${ }^{39}$ Para ello, los municipios fueron traspasados al Régimen Interior del Estado, poniéndolos bajo la autoridad directa del Ejecutivo, arrancándolos de las manos de los partidos y la "lucha por el poder local", según afirmaba el general Pinochet, de modo que "El alcalde es designado por el Ejecutivo y la municipalidad se conduce bajo la inspiración de los intereses nacionales. En lo que a la comuna se refiere, el alcalde es el representante del Presidente de 1a República a nivel local". ${ }^{40}$ Esto confirmaba la concepción centralista de los debates de la

39. General Augusto Pinochet en Actas del Primer Congreso de Alcaldes, 1978, p.19. Aunque la articulación clara de la municipalización ocurrió a partir de 1979, las líneas centrales estuvieron desde un comienzo. La Ley de municipalidades se dictó en 1975. VALDIVIA, Verónica, ALVAREZ, Rolando y DONOSO, Karen, $L a$ alcaldización de la politica. Los municipios en la dictadura pinochetista, Lom, Santiago, 2012.

40. Acta del primer Congreso de Alcaldes..., Op. Cit., p. 20. 
Junta a comienzos de la dictadura, en la cual el principio de la representación desaparecía bajo los objetivos nacionales.

A pesar de que la municipalización tardó cinco años en articularse del todo, las Actas de la Junta de Gobierno y otros documentos de la época confirman la centralidad que desde un principio se le asignó al municipio y, mientras los partidos no marxistas fueron declarados en receso, los municipios recayeron en manos de militares en retiro, incentivándose también la presencia de suboficiales del Ejército y de la policía, Carabineros, regularizándose el nombramiento de ediles y las juntas de vecinos se mantuvieron. ${ }^{41}$ Siguiendo la lógica centralizadora, fue el Ministerio del Interior el que promovió, a través de la Consejería Nacional de Desarrollo Social del Ministerio de Vivienda, la integración de la comunidad desde sus orgánicas comunitarias, ahora despolitizadas, o sea, ajenas al dominio partidario, ordenando su reempadronamiento, regularizando su dirigencias y vigilando sus actividades. Un estrecho vínculo se estableció entre las organizaciones territoriales $y$ funcionales, el municipio y el Ejecutivo. ${ }^{42}$ En otras palabras, de los organismos intermediadores, la dictadura sólo reconoció como tales a las organizaciones territoriales y funcionales, pero desconociéndoles cualquier autonomía e iniciativa, lo cual era consistente con la redefinición de la participación, purgada de sus aristas confrontacionales.

La ley de enero de 1976 definió al municipio como una institución de derecho

41. Actas de la Junta de Gobierno Actas No 19 de 10 de octubre de 1973 y No11 de 28 de septiembre de 1973.

42. Ministerio del Interior, Las organizaciones comunitarias y la restauración nacional, Santiago, 1974. público, funcional y territorialmente descentralizada, cuya función era la satisfacción de las necesidades de la comunidad local, la participación en la planificación y ejecución del desarrollo económico y social de la comuna, de forma independiente, o actuando en coordinación con otros municipios, con otros servicios públicos y organismos del sector privado. Por ello, desde 1979 se traspasaron a su administración -se municipalizaronlos servicios de educación y salud así como los subsidios sociales. Las personas ya no acudirían al Estado central en sus demandas, sino al municipio, el que ejecutaría las políticas sociales definidas por el nivel nacional y regional. E1 Estado financiaba al municipio, de modo que este identificara a quienes requerían de apoyo social, los extremadamente pobres, los que acudirían al sistema educacional municipalizado o particular subvencionado, en el cual participaban, igualmente, los privados a través de las Corporaciones municipales. Así, el desarrollo social era definido por el nivel nacional, incorporaba la colaboración del empresariado y los pobladores eran los destinatarios de esas políticas. ${ }^{43}$

La participación seguía la lógica verticalista de toda la estructuración social, estando a la cabeza del municipio y la comuna el alcalde, designado por el general Pinochet, ejecutor de las políticas de desarrollo definidas en el nivel nacional y regional, y encargado de incorporar a esas diferentes tareas a los actores sociales predefinidos. Los habitantes de la comuna serían integrados a este proceso en el Consejo de Desarrollo Comunal, presidido por el mismo

43. En materia educacional, los colegios particulares subvencionados son propiedad de privados, quienes reciben del Estado una subvención por cada estudiante. En las Corporaciones Municipales, que regulan el tema educacional, participa el alcalde y los privados. 
alcalde y compuesto por los representantes de las organizaciones comunitarias y de las denominadas actividades relevantes, industriales y de comerciantes. Los vecinos estarían representados a través de las juntas de vecinos, centros de madres, centros juveniles y deportivos, todas controladas por el gobierno. Era allí donde el hombre "vive con su familia, ahí le interesa la plaza de juegos creativos, le interesan los árboles... los servicios de las municipalidades... la locomoción, los servicios públicos... el colegio", ${ }^{44}$ el lugar donde, según Pinochet, se expresaban los grupos organizados que daban vida a la comunidad como sistema social. ${ }^{45}$

La función de estas organizaciones era asesorar al alcalde en las tareas ejecutadas por el municipio, actuando como canal de comunicación entre gobernantes y gobernados, pues a través de ellas la autoridad comunal conocería los problemas e inquietudes de la población, pudiendo planificar más eficientemente las políticas municipales.

Es interesante que esta ley de municipios fuera aprobada cuando la disputa entre corporativistas y neoliberales aún no había sido resuelta y los primeros ejercían fuerte influencia en el estamento militar. La pugna, como se sabe, fue resuelta a favor de los planteamientos de los tecnócratas neoliberales, quienes transformaron sus originales propuestas de estabilización monetarista en un proyecto global, que desplegó las fuerzas del mercado al conjunto económico, social y cultural del país, lo cual quedó asegurado constitucionalmente a inicios de los años

44. General René Vidal, Acta del 1er. Congreso Nacional de Alcaldes, 1978, p.71.

45. Acta $2^{\circ}$ Congreso Nacional de Alcaldes, 1980, pp. 19-20. ochenta. No obstante, el triunfo neoliberal se acopló al corporativismo, en tanto la estructuración por niveles se adecuaba a su forma de entender la toma de decisiones, dentro de la cual el escalón comunal podía favorecer la eficiencia. Si para el pensamiento corporativo, que todavía persistía en la mentalidad militar, especialmente en el Ejército y la Fuerza Aérea, las orgánicas comunitarias eran expresión de la comunidad organizada, del cuerpo de la nación y por eso debían integrarse al nivel comunal, para los neoliberales la participación de estas entidades ofrecería la información requerida para una gestión eficiente. En efecto, a pesar de su individualismo, los neoliberales no se opusieron a la municipalización como nueva forma de hacer política, pues eran partidarios de la participación social, consultiva, ya que ésta incrementa la racionalidad y eficiencia administrativa al considerar las opiniones e intereses de la población, desligándolos, aparentemente, de planteamientos explícitamente ideológicos y globales, encauzando el trabajo y reduciendo la resistencia al cambio. ${ }^{46}$ Esas lógicas van consolidando la primacía de lo territorial local en el desarrollo social, favoreciendo la descentralización del Estado, colocando las políticas sociales bajo control de la autoridad local y permitiendo mayor eficiencia en la definición de planes y programas que responderían a los problemas e intereses locales. Se trataría, en todo caso, de un proceso de desconcentración, más que de des-centralización, pues ésta implica la creación de organismos que no dependen jerárquicamente de un poder central y de recursos para administrar y gobernar un territorio. La desconcentración, en cambio,

46. GUERRA, Carlos, Nueva estrategia neoliberal. La participación ciudadana en Chile, UNAM, Cuernavaca, 1997, pp. 66 y 78. Esta parte sobre neoliberalismo y participación está extraída de este texto. 
es una simple transferencia de competencias de organismos superiores a inferiores, pero bajo la subordinación jerárquica del poder central. Consistente con esto, la participación de las personas $\mathrm{y} / \mathrm{u}$ organizaciones sociales es contemplada, pero con carácter consultivo y no decisorio, de manera de focalizar el gasto, integrar a los pobres a la resolución de sus problemas y alcanzar la eficiencia.

En suma, la municipalización permitió controlar centralizadamente a la población, la que fue radicada en ese escalón, sin capacidades decisorias, solo consultivas, mientras los representantes de las "actividades relevantes" eran incorporados al desarrollo social, pudiendo invertir en áreas de infraestructura, como de servicios sociales. Mientras el Estado retrocedía económica y socialmente, los privados entraban con sus capitales a "participar" a los niveles regional y nacional.

\section{Conclusiones}

Los procesos de regionalización y municipalización implementados por la dictadura pinochetista perduran hasta la actualidad en Chile. Durante los años noventa, los alcaldes se transformaron en actores políticos de primera magnitud, frente al retroceso de parlamentarios y dirigentes de partidos, habiendo quienes planteaban reproducir su estilo político local a nivel nacional. Ese estilo se caracteriza por liderazgos personalistas y una gestión focalizada en cuestiones concretas de la comuna, aparentemente ajenas a las políticas de orden general. Este protagonismo alcaldicio fue posible por la mantención de la reforma municipal dictatorial en democracia yla pérdida de legitimidad de la acción parlamentaria y partidista, pues la gestión de los ediles suponía pragmatismo, rechazo a las ideologías, como sinónimo de eficiencia. En los noventa, hubo un consenso de la elite política en torno al neoliberalismo, la elitización de las decisiones en el nivel nacional, mientras la población se concentraba en los problemas comunales, alejada de cuestiones programáticas. La desafección político-partidista fue a la par del auge de los alcaldes.

Si bien el neoliberalismo y la globalización han debilitado la política en todas partes, en Chile ese proceso también se relacionó con el vínculo que la alianza cívico-militar le asignaba al estancamiento y la pobreza en la atracción que ejercían las ideologías denominadas subversivas. $\mathrm{Su}$ derrota requería de modernización económica y una redefinición de la política, en lo cual el control territorial y el escalonamiento de las decisiones y la participación eran claves. La geopolítica ofreció algunas respuestas a esos dilemas. La regionalización fue uno de los instrumentos utilizados para potenciar las regiones y el crecimiento económico a través de un regreso a un modelo primario-exportador, a la vez que para des-concentrar las decisiones y la participación.

La regionalización fue percibida no solo como una medida geográfica, sino como un instrumento de gobierno, de administración y de participación social, pues permitía definir niveles decisionales y la incorporación de los actores sociales. Este escalonamiento por niveles favoreció el centralismo y la toma de decisiones en el nivel nacional, el que definía programáticamente y solo delegaba funciones a los niveles regional y comunal. 
La democracia dictatorial suponía una participación colaborativa, no confrontacional, y sólo consultiva, la que transcurría en la escala comunal. Los municipios eran únicamente ejecutores de las políticas diseñadas en el nivel nacional y puestas en vigor en la región. Por ello, las decisiones del nivel comunal parecían disociadas de lo nacional, aunque eran su materialización: la neoliberalización de los servicios sociales, privatizados $\mathrm{o}$ municipalizados. Los alcaldes parecían sus promotores, aunque sólo eran y son, sus ejecutores.

En concreto, la despolitización social buscada por todas las dictaduras del Cono Sur, en Chile se apoyó no sólo en el terror y el mercado, sino también en el escalonamiento decisional, posibilitado por la regionalización y la municipalización.

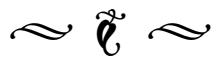

Recibido: 13/03/2015

Aceptado: 23/06/2015

Publicado: 31/07/2015 